\title{
Method for Determination of the Internal Short Resistance and Heat Evolution at Different Mechanical Loads of a Lithium Ion Battery Cell Based on Dummy Pouch Cells
}

\author{
Theo Volck ${ }^{1, *}$, Wolfgang Sinz ${ }^{1}$, Gregor Gstrein ${ }^{1}$, Christoph Breitfuss ${ }^{1}$, Simon F. Heindl ${ }^{1}$, \\ Hermann Steffan ${ }^{1}$, Stefan Freunberger ${ }^{2}$, Martin Wilkening ${ }^{2}$, Marlena Uitz ${ }^{2}$, Clemens Fink ${ }^{3}$ \\ and Alexander Geier ${ }^{4}$ \\ 1 VSI-Institute for Vehicle Safety, Inffeldgasse 23/I, Graz University of Technology, 8010 Graz, Austria; \\ wolfgang.sinz@tugraz.at (W.S.); gregor.gstrein@tugraz.at (G.G.); christoph.breitfuss@tugraz.at (C.B.); \\ simon.heindl@tugraz.at (S.F.H.); h.steffan@tugraz.at (H.S.) \\ 2 ICTM-Institute for Chemistry and Technology of Materials, Graz University of Technology, \\ Stremayrgasse 9, 8010 Graz, Austria; freunberger@tugraz.at (S.F.); wilkening@tugraz.at (M.W.); \\ marlena.uitz@tugraz.at (M.U.) \\ 3 AVL List GmbH, Hans-List-Platz 1, 8020 Graz, Austria; clemens.fink@avl.com \\ 4 Audi AG, Auto-Union-Strasse 1, 85045 Ingolstadt, Germany; alexander.geier@audi.de \\ * Correspondence: volck@gmx.at; Tel.: +43-664-4605406
}

Academic Editor: Juan Carlos Álvarez Antón

Received: 4 January 2016; Accepted: 30 March 2016; Published: 7 April 2016

\begin{abstract}
Within the scope of developing a multi-physical model describing battery behavior during and after the mechanical load (accelerations, intrusions) of a vehicle's high voltage battery, an internal short circuit model is of deep interest for a virtual hazard assessment. The internal short resistance and the size of the affected area must be known as a minimum for determining the released heat and, in consequence, the temperatures. The internal short resistance of purpose-built dummy pouch cells, filled with electrolyte-like solvent without conductive salt, has thus been measured in a given short area under various compressive loads. The resistances for different short scenarios obtained are analyzed and described in a mathematical form. Short circuit experiments with dummy cells using an external power source have also been carried out. This set-up allows the measurement of the temperature evolution at a known current and a determination of the actual short resistance. The post-mortem analysis of the samples shows a correlation between the maximum temperatures, released short heat and the separator melt diameter.
\end{abstract}

Keywords: internal short-circuit modeling; contact resistance; mechanical load; current measurement; thermal behavior; separator melt

\section{Introduction}

The protection of a vehicle's traction battery from crash-related damage is a priority focus in most current electric vehicle (EV) and hybrid electric vehicle (HEV) designs. Battery failure induced by mechanical loads (acceleration and/or intrusion) can lead to electrical and chemical hazards together with fire, which can result in serious danger to life, the environment and the infrastructure [1,2] and should therefore not occur in the field. This explains today's design guidelines for vehicle batteries, where deformation and excessive accelerations in case of a crash are not acceptable for most original equipment manufacturers (OEMs). Battery packs of HEVs are mostly relatively small and placed in well protected areas where intrusion of foreign objects is unlikely to appear. For example the Audi 
Q5 Hybrid and the BMW ActiveHybrid 3 use a battery encased in a high-strength housing placed between the rear wheels in the trunk [3].

Plug-in hybrid EVs or pure EVs use much larger batteries which must be well integrated into the vehicles structure. The two most common design concepts are the "T-architecture" and the "floor architecture", each with its advantages and limitations [4].

It is expected that other architectures will bring advantages, for example increased usable battery space and therefore increased capacity and vehicle range. These architectures may be limited by safety concerns resulting from battery installation in less protected areas (e.g., between front wheels) where intrusions are more likely to appear. The design process for such architecture must be supported by advanced tools for better understanding of the cell behavior during and after mechanical loads. In the area of computer-aided engineering a virtual hazard assessment based on simulations may be such a tool in the future. Current research projects (e.g., [5]) are attempting to investigate the mechanical and the electrical/thermal behavior of crushed battery cells to combine the results in a "hybrid approach" enabling such an assessment. For this approach, simulation models with prediction capabilities for both mechanical and electrical/thermal behavior must be available.

Although there have been approaches published in the literature to couple mechanical-electrical-thermal models, as developed by Zhang et al. [6] or Heindl et al. [7], the models are mostly developed separately.

The investigation and simulation of mechanical behavior of a battery cell with respect to a battery pack is a priority focus of current research. For example, Breitfuss et al. [8] and Sahraei et al. [9] presented finite element (FE) models of a pouch-type lithium-ion cell. Furthermore, for example, Greve and Fehrenbach [10] presented a FE model of a cylindrical lithium-ion cell.

Parallel studies have been published which deal with electrical/thermal modeling of a battery in normal discharge and under internal short circuit conditions. Besides equivalent circuit models [11] or models based on cell charge/discharge tests and data sheet [12], most of the battery models currently used for research, development and battery optimization are mathematical micro-scale models allowing the correlation of the theoretical results with experimental transport and electrochemistry data [13]. They are mostly based on the Doyle/Fuller/Newman model [13].

For modeling of the internal short circuit not only battery behavior under discharge conditions is necessary but also knowledge about the short itself. The heat generation on the short spot and the entire cell is of great interest for a thermal assessment of an internally shorted cell. The sources are a combination of electrical, electrochemical and chemical heat. Maleki and Howard [14] described an approach for modeling the heat sources and estimating the necessary input parameters. In the most recent works the short is either modeled as a one layer contact surface [15] or a volume (e.g., a nail) [16] connecting both electrodes. The electrical heat generation of the spot is described by the Ohmic heat and is computed with a parameter referred to as the short resistance, times the square of the short current through the affected area. The resistance is more or less a property of the short spot that can scarcely be determined.

How can it be possible to determine the short resistance for a given shorted cell, or respectively for a model of the cell?

Various test methods for creating an internal-short under controlled conditions in a finished functioning cell (live-cell) with all their advantages and disadvantages [14] have been published. In the current state of the art it is not possible to perform short resistance measurements in a finished cell, but assessments to estimate the short resistance have been carried out instead. Fang et al. [17] used the short resistance as a fitting parameter to match the experimental data, especially the cell voltage. Without proof, it would appear obvious that the voltage drop measured at the cell contacts must give some information about the actual current if discharge data of the cell at an appropriate c-rate is available. It is apparent from the literature that this technique has not been used for internal short current estimation. 
This paper presents a new method for generating internal short resistance data based on measurements in combination with a mechanical load and short circuit experiments at a known current using lithium iron phosphate (LFP) cells. This data may allow a deeper understanding of the internal shorts and their modeling in computational approaches.

\section{Method}

\subsection{General}

The common methods for investigating the internal short behavior of lithium-ion batteries involve conducting risky tests. The use of functional cells, also known as live-cells, increases the risk of a thermal runaway occurring. These tests are thus performed in a fire-proof environment $[2,18]$. Furthermore the investigation of the test specimen and reconstruction of the events during and after the test is virtually impossible to implement since thermal destruction cannot be reversed once started. Based on these facts the methods would appear to be inappropriate for gaining a deeper understanding of internal shorts.

The method presented here makes use of our own constructed, non-active cells filled with surrogate electrolyte without salt, also referred to as dummy-cells. Since the cells are volt-free direct current (DC) resistance measurement on an internally shortened sample can be performed easily under laboratory conditions with low safety requirements. Furthermore, the dummy-cells cannot be charged if connected to an external power source. Therefore the internal short circuit in a sample can be supplied externally at a known current while having the option to measure the short resistance.

The use of a switchable short circuit element, as presented by National Renewable Energy Laboratory (NREL) [19] or by Ramadass et al. [17] is not necessary for this method, which results in an easy and safe test set-up. The samples can be loaded mechanically to investigate the effects of mechanical loads on the short resistance. In the samples a copper particle with a defined short area $\left(1 \mathrm{~mm}^{2}\right)$ and thickness $(0.2 \mathrm{~mm})$ is placed in the hole of a punched $20 \mu \mathrm{m}$ polyethylene (PE) separator type Celgard K2045. This particle leads to an electrical connection between both electrodes at a constant short circuit area. This set-up may not represent all real life mechanical cases but allows defined and reproducible shorting of the samples. The idea is to use these results as an interface between a mechanical model and an electro-thermal or electrochemical model.

Two different types of tests, namely resistance measurement and internal short circuit experiments, were performed and will be described in the following two subsections.

Both resistance measurement and internal short circuit experiments use electric current to generate a voltage drop via the sample to make conclusions about the resistance. The current also leads to a heating of the short spot. Heating of the spot must be avoided during the resistance measurement to avoid thermal influence. By contrast, heat generation is in focus during the realized internal short circuit experiments. The resistance of the sample can be determined by the Ohmic law given by the formula $R_{\mathrm{S}}=U_{\mathrm{C}} / I$, where $R_{\mathrm{S}}$ is the sample or short resistance, $U_{\mathrm{C}}$ is the voltage drop via the cell and $I$ is the actual current. The released heat $Q_{S}$ at the internal short can be calculated with $Q_{S}=U_{C} \times I$. As mentioned before, $Q_{S}$ should be low during the resistance measurement to avoid thermal influence. The load cases for resistance measurement and short circuit experiments are summarized in Table 1.

This method would appear suitable for producing data unaffected by electrochemical and chemical heat sources with a focus on the internal short circuit, the resistance and the released heat. The samples can be prepared to represent any possible contact situation which can occur in a live-cell.

The differences between resistance measurement and short circuit experiments will be discussed in the subsections below. 
Table 1. Load case compilation for resistance measurements and short circuit experiments. Al-An: aluminum current collector vs. anode material; and An-Ca: anode material vs. cathode material.

\begin{tabular}{|c|c|c|c|c|c|c|}
\hline $\begin{array}{l}\text { Contact } \\
\text { Situation }\end{array}$ & $\begin{array}{l}\text { No. of } \\
\text { Samples }\end{array}$ & Scope & Short Area & Stress (Force) & Current & Temperature \\
\hline $\mathrm{Cu}-\mathrm{Al}$ reference & 10 & \multirow{8}{*}{$\begin{array}{c}\text { Resistance } \\
\text { measurement }\end{array}$} & \multirow{8}{*}{$1 \mathrm{~mm}^{2}$} & \multirow{8}{*}{$\begin{array}{c}0-100 \mathrm{MPa}(\mathrm{N}) \\
\text { every } 10 \mathrm{MPa} \\
(\mathrm{N}), 200 \mathrm{MPa}, \\
400 \mathrm{MPa}\end{array}$} & \multirow{8}{*}{$\begin{array}{c}\text { Range } \\
30-300 \mathrm{~m} \Omega \\
\rightarrow 200 \mathrm{~mA} ; \\
\text { range 3-30 } \\
\Omega \rightarrow 20 \mathrm{~mA}\end{array}$} & \multirow{8}{*}{$\begin{array}{l}\text { Ambient } \\
\text { temperature } \\
\sim 25^{\circ} \mathrm{C}\end{array}$} \\
\hline $\mathrm{Cu}-\mathrm{Al}$ electrolyte & 10 & & & & & \\
\hline $\mathrm{Cu}-\mathrm{Ca}$ reference & 10 & & & & & \\
\hline $\mathrm{Cu}$-Ca electrolyte & 10 & & & & & \\
\hline Al-An reference & 10 & & & & & \\
\hline Al-An electrolyte & 10 & & & & & \\
\hline An-Ca reference & 10 & & & & & \\
\hline An-Ca electrolyte & 10 & & & & & \\
\hline \multirow{3}{*}{$\begin{array}{l}\text { Al-An short tall } \\
\text { sample }\end{array}$} & \multirow{3}{*}{3} & \multirow{3}{*}{ Temperature } & \multirow{3}{*}{$1 \mathrm{~mm}^{2}$} & \multirow{3}{*}{$\sim 20 \mathrm{MPa}$} & \multirow{3}{*}{$\sim 6 \mathrm{~A}$} & Max. $\sim 100{ }^{\circ} \mathrm{C}$ \\
\hline & & & & & & Max. $\sim 120^{\circ} \mathrm{C}$ \\
\hline & & & & & & Max. $\sim 250^{\circ} \mathrm{C}$ \\
\hline
\end{tabular}

\subsection{Resistance Measurements}

The resistance measurement is performed with DC methods since the internal short in a cell is a DC discharge event. The voltage drop (due to current) between the two cell tabs represents the resistance of the whole sample. The relevant short resistance for ohmic heat generation mainly consists of the resistance of the electrode materials $R_{\text {anode }}$ and $R_{\text {cathode }}$ and the interface resistance $R_{\text {interface }}$ to the particle. The resistance of the current collectors and the particle is neglected since the metals used are excellent conductors. Figure 1 shows how the dummy-cell resistance is combined and its dominant portions. The interface resistance $R_{\text {interface }}$ is only expected to be relevant between particles and electrodes. The resistance between the electrode material and current collector scarcely needs to be taken into account since this is not really an interface between separate components of the cell. The electrodes are therefore modelled as a combination of one component with a dominant resistance portion (electrode material) and one with a negligible resistance (current collector). The classification of the resistances $R_{\text {anode }}, R_{\text {cathode }}$ and $R_{\text {interface }}$ is used just to clarify the relevant portions of the measured resistance but does not mean that these portions can be determined separately with the method as demonstrated. The measured resistance is always the one of the whole sample and will not be corrected to determine local resistance portions.

The sample resistance is the focus of the investigation during the resistance measurements. To achieve a good accuracy, a METRAHIT 27I type milliohm meter (GMC-I Messtechnik GmbH, Nuremberg, Germany) is used. This meter operates on the principle of the four-wire technique. This technique allows a more precise resistance measurement without influence of the measurement lines. To analyze the influence of mechanical loads in the short spot on the short resistance, the samples are loaded using a compressive force. The mechanical load dependency of the contact resistance is e.g., for metallic parts described by Holm [20] and shows that an increase of the compressive force leads to a decrease of the contact resistance. It is expected that an electric contact between the two electrodes of the cell will also behave in a similar manner.

The ambient temperature and surface roughness are constant during the measurement. The mechanical load is limited to a compressive stress of $400 \mathrm{MPa}$ in the short area, since this is beyond the strength of the cell materials. To achieve a good resolution of the stress/resistance relation, the expected relevant range from 0 to $100 \mathrm{MPa}$ is tested in $10 \mathrm{MPa}$ steps. Samples without electrolyte are tested as a reference in order to estimate the influence of the surrogate electrolyte. Since Holm [20] stated the statistical nature of the contact resistance, at least ten valid measurements per load case must be achieved. A valid measurement occurs if the resistance is definitely above the resistance of direct metallic contact below a stress of $50 \mathrm{MPa}$. All other measurements are specified as invalid. Since it 
is expected that the stress will lead to an indentation of the particle, the results of the measurements performed are valid only for cells with a similar lay-up thickness (see Figure 1, portions of the short resistance). Other thicknesses may lead to a different stress/resistance relation. Since the possible area change due to pressure was very small and therefore neglected, the short circuit area was assumed constant with $1 \mathrm{~mm}^{2}$. This leads to the correlation that the value of the compressive stress in MPa is equal to the press force in $\mathrm{N}$.

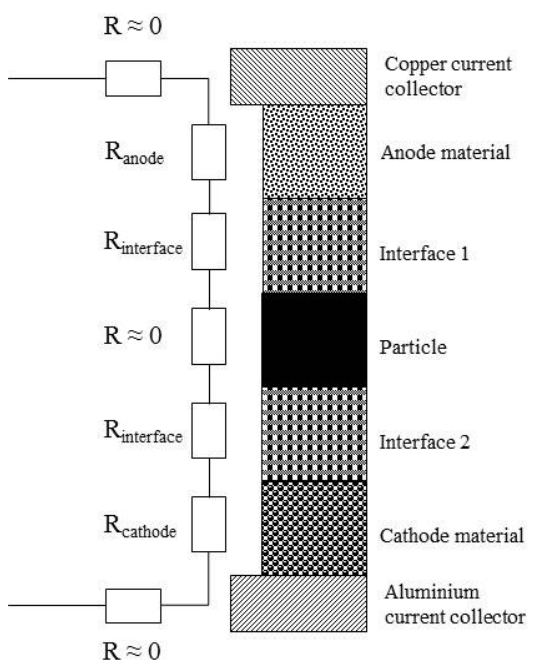

Figure 1. Possible current path via a shorting particle in a dummy cell. Relevant resistance portions are mainly the interface resistance and the electrode material resistance.

The overall setup of the resistance measurement is shown in Figure 2a. The sample is fixated in an insulating device with the clamps of the milliohm meter. The supports to transfer the load to the particle are made of acrylic glass in order to avoid bypass current and to assure a constant short circuit area by applying the load only to the elevated particle. The device is then mounted in a screw press to apply the load. The load was increased to the desired value at a speed of $10 \mathrm{~mm} / \mathrm{min}$. The measurement of one testing point was performed once the desired load was reached and the movement of the press had stopped. As mentioned before the cell contact, resistance is expected to be approximately zero and is therefore negligible.
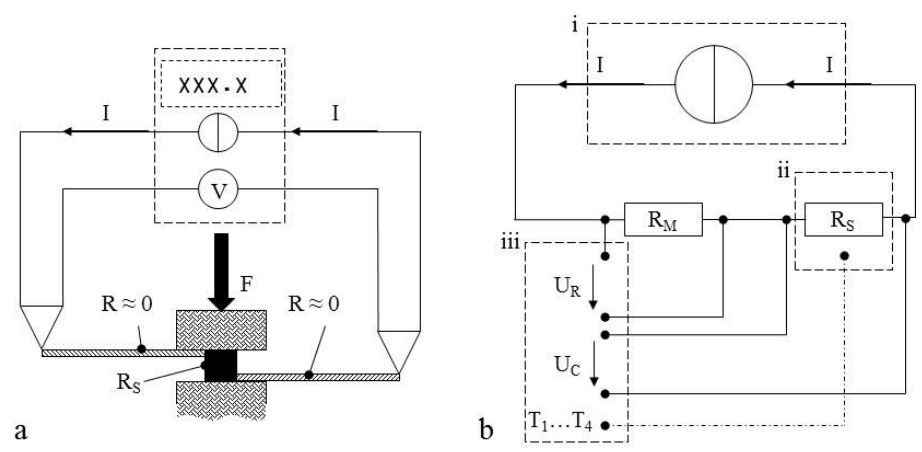

Figure 2. (a) Measurement set-up of the resistance measurements: four-wire technique, sample mounted in a press. (b) Internal short circuit test set-up: Current source (i) is connected with shunt and cell in adiabatic housing with temperature sensors (ii). Voltage drops and temperatures are recorded by a signal processing unit (iii). 


\subsection{Internal Short Circuit Experiments}

The thermal behavior of the taller short circuit samples is investigated at a much higher current than that used for resistance measurement. The internal short circuit samples described in Figure 3Ib are connected to a test set-up as shown in Figure $2 \mathrm{~b}$. The sample is covered with styrene to avoid the influence of draught and unknown heat transfer (adiabatic set-up). This also allows a little pretensioning of the particle to obtain a lower resistance short and to have a more stable resistance value should the cell begin to blow up to some limited extent. The experiments will be stopped by cutting of the current if the surface temperature at the short spot reaches approximately $100{ }^{\circ} \mathrm{C}, 120^{\circ} \mathrm{C}$ or $250^{\circ} \mathrm{C}$. To determine a realistic current, the observed resistance of the aluminum current collector versus anode material (Al-An) pair was used as a base for calculation. The resistance of the Al-An pair is in the range of approximately $0.3-3 \Omega$ (these values were determined iteratively) which leads to currents in the range of 1-12 A based on the Ohmic law. As base for calculation a cell voltage of 3.6 V, based on LFP cells, was chosen. Finally, $6 \mathrm{~A}$ were chosen since this was the limit of the used power source.
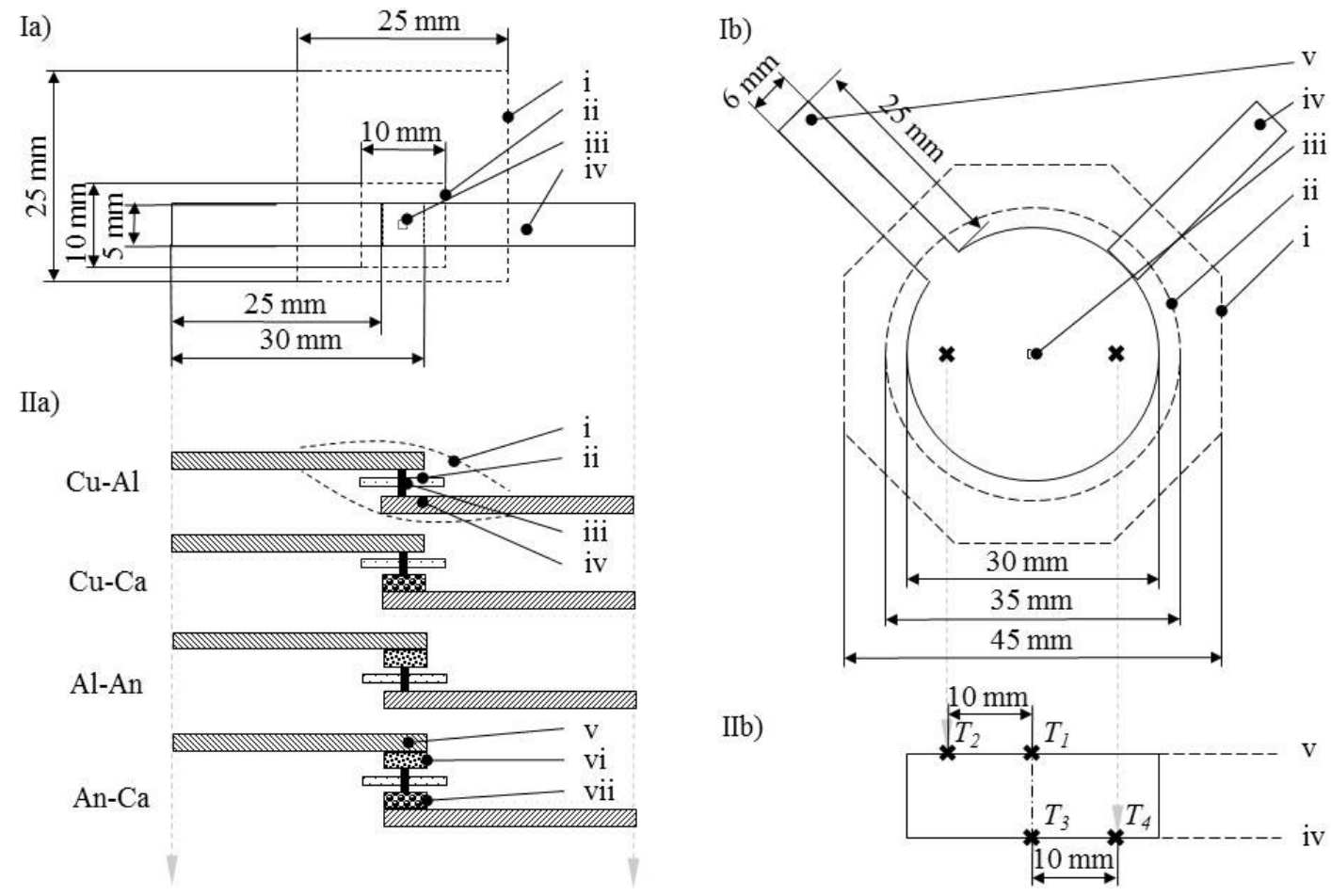

Figure 3. (Ia) Dimensions of resistance sample components; (Ib) dimensions of short circuit samples; (IIa) possible combinations of current collectors with/without electrode material (thickness not to scale); and (IIb) radial position of temperature sensors on cell surface (thickness not to scale). Numeration: (i) pouch housing; (ii) separator; (iii) particle; (iv) PCC; (v) negative current collector (NCC); (vi) An; and (vii) Ca.

Three samples of the Al-An contact situation are tested at the three different maximum temperatures (Table 1) to evaluate the influence of maximum heat on the separator melt. Since the power source draws nearly the same power depending on the contact resistance, the overall energy released at the short spot is mainly time-dependent. The temperature of the samples is measured at four points. 


\section{Contact Situations}

In a common lithium-ion cell, the four voltage-carrying materials copper, anode, cathode and aluminum may come into contact due to a malfunction of the separator as the insulating element between the two electrodes. Santhanagopalan et al. [21] described the four possible contact situations and their characteristics. These will be repeated here briefly for a better understanding of the test results and the tendencies. A compilation of the contact situations is given in Figure 4.

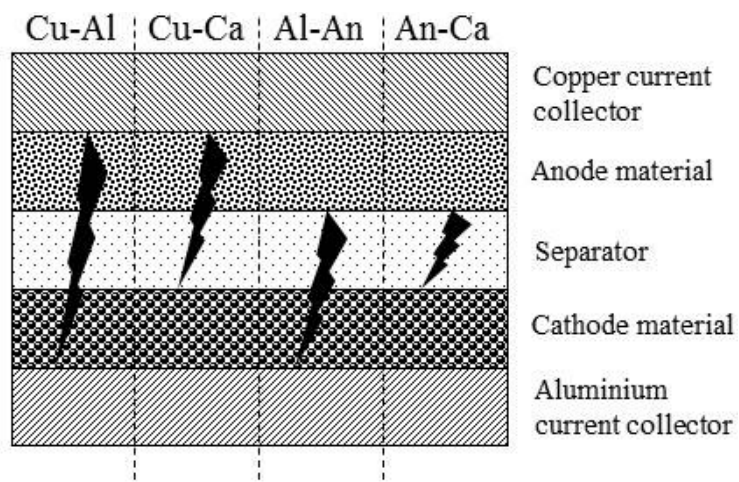

Figure 4. Possible short circuit scenarios in a lithium-ion cell: lay-up of a common lithium-ion cell with current collectors, separator and electrode materials; lightning symbolizes possible position of electrical connection.

Copper current collector versus aluminum current collector $(\mathrm{Cu}-\mathrm{Al})$ : This short scenario has a relative similarity to a low resistance contact of the cell tabs. The released energy is the highest of all shorts due to the low resistance of the involved materials. Since aluminum and copper are also good heat conductors the stored heat at the short is low. The short resistance to be expected is $\sim 10 \mathrm{~m} \Omega$ [22].

Copper current collector versus cathode material $(\mathrm{Cu}-\mathrm{Ca})$ : The resistance of this short scenario is given by the cathode material since it is one of the poorest conductors among the four relevant materials. The heat release is usually not sufficient to trigger any further chemical reactions. The expected short resistance is $>100 \mathrm{~m} \Omega$ [22].

Al-An: The resistance of this short scenario is provided by the anode material graphite. Conversely to the $\mathrm{Cu}$-Ca short the anode material has a low electrical resistance, making the Al-An scenario a low-resistance and therefore high-power short. In addition the onset temperatures for anode reactions are low compared to those on the cathode and the thermal conductivity of the anode material is very low leading to high temperatures at the spot. This makes the Al-An short the worst-case scenario of what can happen to a cell. The resistance to be expected is $\sim 100 \mathrm{~m} \Omega$ [22].

Anode material versus cathode material (An-Ca): This is the most probable short scenario inside a cell. The resistance is given by the poor conductivity of the cathode which makes it the preferential case in practice. The expected resistance is $>>100 \mathrm{~m} \Omega$ [22].

Table 2 shows a compilation of the contact situation properties with a focus on the potential risk. The symbols used are - for a high risk, o for intermediate risk and + for low risk.

Table 2. Compilation of contact situations behavior and risk potential.

\begin{tabular}{ccccc}
\hline Contact Situation & $\mathrm{Cu}-\mathrm{Al}$ & $\mathrm{Cu}-\mathrm{Ca}$ & $\mathrm{Al}-\mathrm{An}$ & $\mathrm{An}-\mathrm{Ca}$ \\
\hline Expected resistance & $\sim 10 \mathrm{~m} \Omega$ & $>100 \mathrm{~m} \Omega$ & $\sim 100 \mathrm{~m} \Omega$ & $>100 \mathrm{~m} \Omega$ \\
Resistance & - & + & $\mathrm{o}$ & + \\
Heat conduction & + & $\mathrm{o}$ & - & - \\
Short power & - & + & $\mathrm{o}$ & + \\
Local temperature & $\mathrm{o}$ & + & - & + \\
Occurrence & + & $\mathrm{o}$ & $\mathrm{o}$ & - \\
Potential risk & $\mathrm{o}$ & + & - & + \\
\hline
\end{tabular}


These contact situations will be used in the scope of this paper, although the contact is made via a particle the resistance of which is neglected. The short resistance is to be understood as described in Figure 1 and Section 2. This resistance and its thermal behavior are the focus of the further investigation.

\section{Preparation of Samples}

\subsection{General}

The samples used are all made from the same raw materials used for LFP cell manufacture in laboratory scale. Uniform material compositions and application thicknesses are used for the electrodes.

The negative electrode consists of a $20 \mu \mathrm{m}$ thick copper foil and an anode material film with an average thickness of $43 \mu \mathrm{m}$ which is a common range for an automotive battery. The anode material is a mixture of graphite KS $6(90 \% \mathrm{w} / \mathrm{w}$, TIMCAL, Bodio, Switzerland), carbon black Super C 65 (3\% w/w, TIMCAL) and binder Kynar 761 (7\% w/w, Kynar, King of Prussia, PA, USA) and $\mathrm{N}$-methyl-2-pyrrolidon (NMP, Sigma-Aldrich, St. Louis, MO, USA). The positive electrode consists of a $20 \mu \mathrm{m}$ thick aluminum foil and a cathode material film with an average thickness of $35 \mu \mathrm{m}$ which is below the common range but a sufficient value to avoid crumbling of the material during manufacture. The cathode material is a mixture of LFP ( $82 \% \mathrm{w} / \mathrm{w}$, Süd-Chemie, Munich, Germany), carbon black Super C $65(8 \% \mathrm{w} / \mathrm{w})$ and binder $(10 \% \mathrm{w} / \mathrm{w})$ and NMP. These mixtures are applied on the appropriate metal foil with a film applicator. The electrodes are then dried in an oven at $60^{\circ} \mathrm{C}$ for approximately $12 \mathrm{~h}$. The final electrodes are cut and joined with a piece of $20 \mu \mathrm{m}$ PE separator type Celgard K2045 (Celgard LLC, Charlotte, NC, USA) provided with a small hole (Figure 3Ia ii) where a piece of copper with the dimensions $0.2 \times 1 \times 1 \mathrm{~mm}$ (Figure 3Ia iii) is placed. This arrangement is covered by a fusion welded pouch housing (Figure 3Ia i) filled with $20 \mu \mathrm{L}$ diethyl carbonate (DEC, Sigma-Aldrich) as a surrogate electrolyte.

\subsection{Resistance Samples}

The size of the resistance samples is chosen in a very small range in order to achieve a good fixation of the particle without any further action being necessary (Figure 3Ia). The different short circuit scenarios are established by the current collector combinations (Figure 3IIa iv and v) and with these either coated or not coated with electrode material (Figure 3IIa vi and vii) in the overlap area (Figure 3IIa). The length of the cell contacts results from an easy connection to the clamps of the milliohm meter.

\subsection{Short Circuit Samples}

The internal short circuit samples do not contain electrolytes to avoid safety issues since the experiments will take place in a non-fireproof environment and also to enable a post-mortem analysis of the specimen. The dimensions of these samples are increased compared to the resistance samples so as to gain more space for temperature sensor application. This also leads to a slower thermal response and a sample size which fits the power generated by the current source. The size was also limited by the laboratory equipment. The housing uses an octagonal layout which is a compromise between ease of production and a rotationally symmetric temperature distribution. As mentioned above, the tested contact scenarios for the internal short circuit experiments are limited to the Al-An pair. The particle is held in place simply by the adhesion of the electrode materials if mounted during the film application. In the current state, the cathode material allowed sufficient fixation of the particle on the metal current collector during fabrication and testing. Other contact situations cannot readily be realized with the technique as used.

Figure 3Ib shows the dimensions of the internal short circuit samples used. Figure 3Ilb shows the positions of the temperature sensors used where $T_{1}$ is in the center and $T_{2}$ is at $r=10 \mathrm{~mm}$ at the negative side and $T_{3}$ is in the center and $T_{4}$ is at $r=10 \mathrm{~mm}$ at the positive side. 


\section{Results}

\subsection{Short Resistance Measurements}

The mean value and the standard deviation of the valid measurements (definition in Section 2.2.) are calculated for every possible contact situation (electrolyte or reference sample). Invalid measurements (definition in Section 2.2) have been rejected. Depending on the contact situation $30 \%$ to $40 \%$ of the tested samples were invalid. It is expected that this is caused by the high sensitivity of the samples during handling. This have may cause an indentation of the particle prior the tests.

The results of the $\mathrm{Cu}-\mathrm{Al}$ contact situation are shown in Figure 5a. The value shows good accordance with the $10 \mathrm{~m} \Omega$ given by [22]. An increase of the force leads to a reduction of the short resistance. The reference value is beyond the electrolyte sample value. It is expected that oxygen availability leads to a layer with a higher resistance on the interfaces. Both evolutions show only a minimal decrease above $20 \mathrm{~N}$ meaning that the resistance cannot be reduced by a further increase of the force applied.
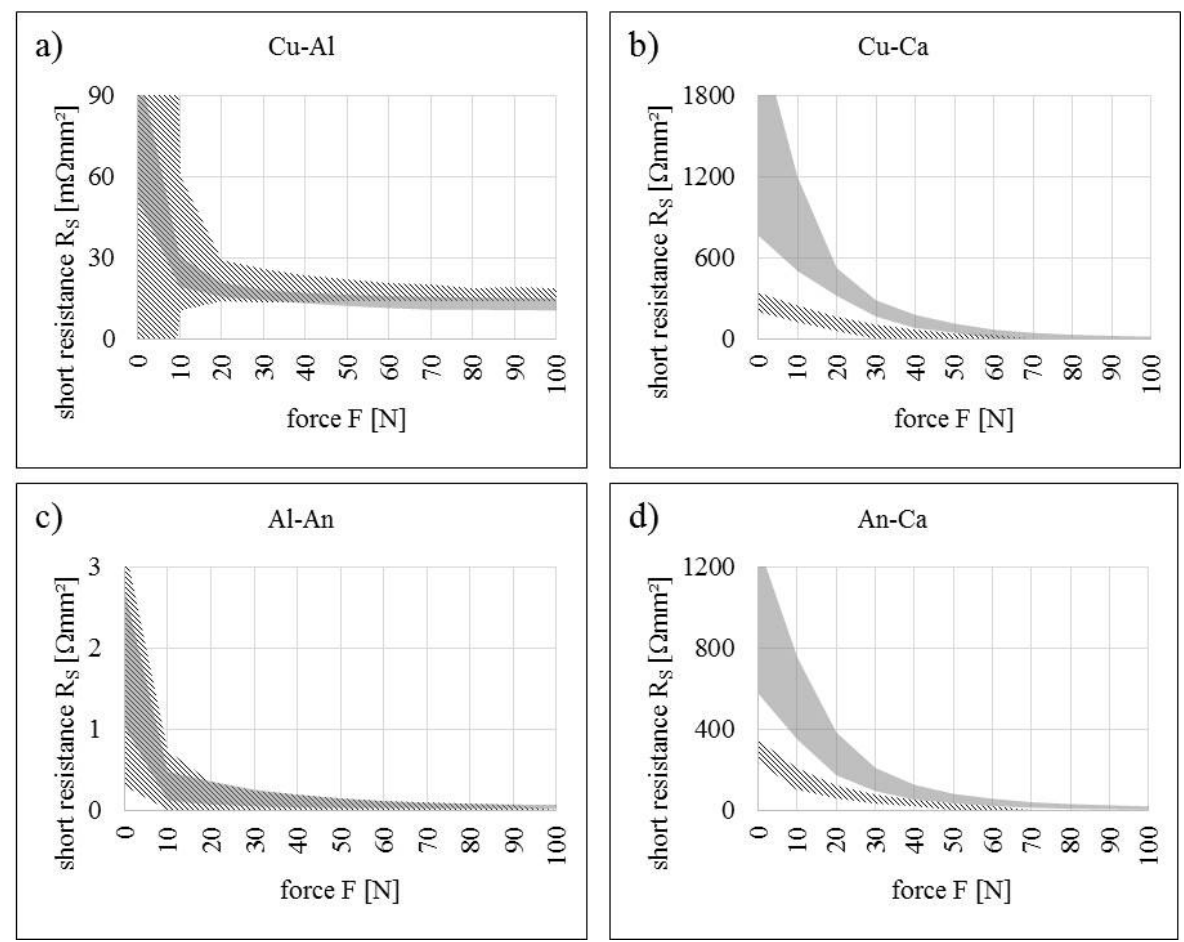

Figure 5. Comparison of resistance measurement (mean value \pm standard deviation): (a) $\mathrm{Cu}-\mathrm{Al}$; (b) $\mathrm{Cu}-\mathrm{Ca}$; (c) Al-An; and (d) An-Ca. Color scheme: shaded = reference samples; grey = samples with electrolyte.

Figure $5 \mathrm{~b}$ shows the results of the $\mathrm{Cu}-\mathrm{Ca}$ contact situation. For higher forces the values show good accordance with the $>>100 \mathrm{~m} \Omega$ given by [22]. At increasing forces the values for both reference samples and electrolyte samples decrease and approach the $\mathrm{Cu}-\mathrm{Al}$ values in the area of $<20 \mathrm{~m} \Omega$. This is clearly apparent since at high loads the particle penetrates the electrode layer and brings about a direct contact with the current collector. The electrolyte samples are beyond the reference over the whole area.

The results of the Al-An contact situation are shown in Figure 5c. The values above $20 \mathrm{~N}$ are in good accordance with the $\sim 100 \mathrm{~m} \Omega$ given by [22]. Reference and electrolyte samples show similar values. An influence of the electrolyte cannot thus be seen in this case. At increasing loads the decrease stagnates to end up at values $<20 \mathrm{~m} \Omega$ analogous to the $\mathrm{Cu}-\mathrm{Al}$ contact situations. 
Figure $5 \mathrm{~d}$ shows the results of the An-Ca contact situation. At higher forces the values show good accordance with the $>>100 \mathrm{~m} \Omega$ given by [22]. At increasing forces the values for both reference samples and electrolyte samples decrease and approach the $\mathrm{Cu}-\mathrm{Al}$ values. The electrolyte samples are beyond the reference over the whole area.

It can be said, in summary, that the electrolyte influences the resistance if LFP is present. The pouch housing appears to have the effect of avoiding oxidation of the current collector metals. The anode material (graphite) resistance is scarcely influenced by the electrolyte.

The resulting mean values have been brought into a mathematical form for future use in a software package. An empirical formula has been developed to reduce the quantity of fitting parameters, and good accordance with the data was shown with only low mathematical effort since polynomial functions showed accordance only at grades higher than 8. The formula is given by $R_{\mathrm{sspec}}=C_{0}+$ $C_{1} /\left(C_{2} \hat{p}\right)+C_{3} \times p$, where $C_{0}, C_{1}, C_{2}$ and $C_{3}$ are constants depending on the contact situation, $p$ is the compressive stress on the particle's contact surface in $\mathrm{MPa}$ (in this case $\mathrm{MPa}$ is equal to $\mathrm{N}$ since the surface is $1 \mathrm{~mm}^{2}$ ) and $R_{\text {sspec }}$ is the specific short resistance of the contact situation in $\Omega \mathrm{mm}^{2}$. The constants for each contact situation are shown in Table 3. To calculate the absolute resistance of a certain element in a simulation mesh representing an internal short circuit in a cell the data may be used in the following sequence. The result of a mechanical model gives information about the occurring contact situation, contact surface and compressive stress of the element. Based on this information, the interface resistance of the element can be calculated according to $R_{\text {selement }}=R_{\text {sspec }} / A_{\text {element }}$, where $R_{\text {selement }}$ is the resistance of the interface and $A_{\text {element }}$ is the short circuit area of the element.

Table 3. Constants for mathematical resistance description.

\begin{tabular}{ccccc}
\hline Contact Case & $\boldsymbol{C}_{\boldsymbol{0}}$ & $\boldsymbol{C}_{\mathbf{1}}$ & $\boldsymbol{C}_{\mathbf{2}}$ & $\boldsymbol{C}_{\mathbf{3}}$ \\
\hline Cu-Al reference & 0.016 & 0.272 & 1.28 & 0 \\
Cu-Al electrolyte & 0.0185 & 0.059 & 1.25 & -0.06 \\
Cu-Ca reference & 2.1 & 270 & 1.047 & 0 \\
Cu-Ca electrolyte & 5.5 & 1522 & 1.065 & 0 \\
Al-An reference & 0.155 & 1.65 & 1.2 & -1.2 \\
Al-An electrolyte & 0.185 & 1.69 & 1.25 & -1.4 \\
An-Ca reference & 2.9 & 294.5 & 1.059 & 0 \\
An-Ca electrolyte & 10 & 934 & 1.062 & 0 \\
\hline
\end{tabular}

\subsection{Internal Short Circuit Experiments}

Figure 6 shows exemplary the evolution of the surface temperatures (enumeration in Figure 3IIb) and the released heat at the short for Sample \#1. The temperatures at the short are higher than those $10 \mathrm{~mm}$ distant in radial direction. This is because the short heat is released mainly at the short center location and cannot be transferred in an appropriate time. In the axial direction the cathode sided temperatures are above the anode sided temperatures. This is due to the lower thermal conductivity of the aluminum (heat conservation at short) and the better heat transfer from the particle to the aluminum foil. By contrast, the anode-sided copper foil enables a good heat transfer in the radial direction and the anode film (graphite) reduces the heat transferred to the cell surface (pouch). This behavior can be observed in all the samples.

Since the samples reach different maximum temperatures, the separator melt diameter $d$ is compared. Post-mortem analysis of the samples shows that the higher the maximum temperature respectively the released short energy $W_{S}$ the wider is the zone affected by separator melt. The short energy is given by $W_{S}=Q_{S} \times t$. The relation of the separator melt diameter $d$ and short energy $W_{S}$ is shown in Figure 7a. Sample \#1 reached $100{ }^{\circ} \mathrm{C}$ and $d \approx 5 \mathrm{~mm}$, Sample $\# 2$ reached $120{ }^{\circ} \mathrm{C}$ and $d \approx 10 \mathrm{~mm}$, and Sample \#3 reached $250^{\circ} \mathrm{C}$ and $d \approx 15 \mathrm{~mm}$. The relation for these three samples follows with good accordance the approximation $d=W_{\mathrm{S}} / 14.5$ (dotted line) but should be verified with more tested samples. Figure $7 \mathrm{~b}$ shows the post-mortem analysis of the samples. 


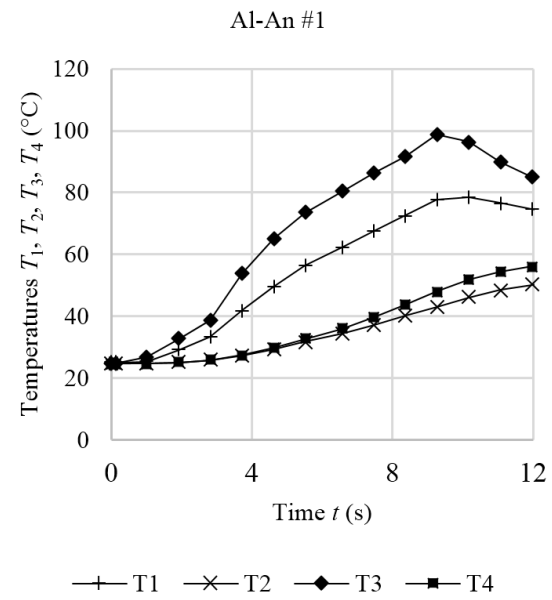

Figure 6. Temperature evolution of internal short circuit Sample \#1: The average heat released at the short is approximately $6 \mathrm{~W}$. Temperatures arranged according to size $T_{3}>T_{1}>T_{4}>T_{2}$; caused by the different radial positions and thermal conductivities.

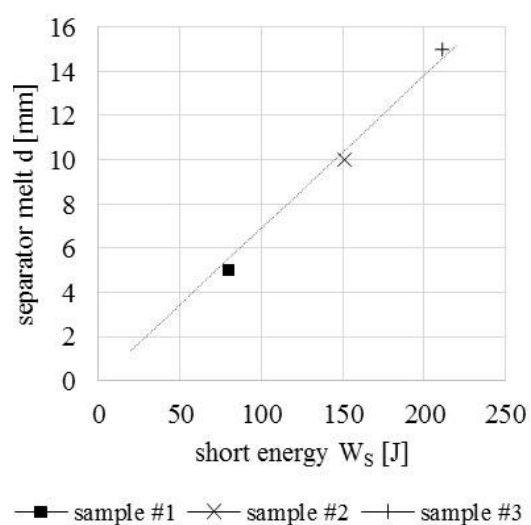

(a)

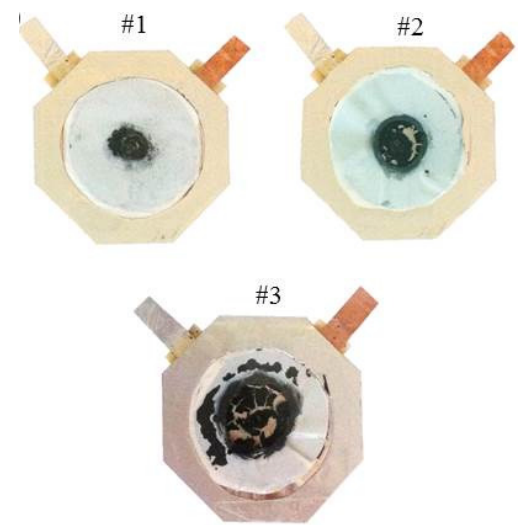

(b)

Figure 7. (a) Relation of Al-An separator melt $d$ and released short energy $W_{\mathrm{S}}$, dotted line shows linear approximation. (b) Separator melt of the short circuit samples (post-mortem analysis).

Since the maximum surface temperature for Samples \#1 and \#2 is below the slumping temperature $\left(>120^{\circ} \mathrm{C}\right)$ of the given separator material $\mathrm{PE}$, it is expected that the inside temperature of the sample is much higher. The efforts made in this study to perform local temperature measurements at the short circuit particle have not yet proved successful. The observation that the surface temperature is not representative for fast internal short detection may be helpful for future safety concept development.

\section{Conclusions}

The presented method allows not only resistance measurements of common contact situations occurring during an internal short circuit in a lithium-ion cell, but also controlled safe internal short circuit experiments without a switchable short element at a given current from an external power source.

Short resistance measurements at different loads enable a correlation between electrical, electrochemical and mechanical models. It is shown that the presence of electrolyte affects the short resistance. Increasing compressive stress reduces the contact resistance in the short area and may change the type of short. Short types with electrode material included lead to higher resistances than direct metallic contact. At high compressive stress, the resistance approaches low resistance values 
in the area of $20 \mathrm{~m} \Omega$. The relation stress versus resistance has been brought in an easy mathematical form for further use in software packages.

The result of a mechanical simulation, which shows the contact situation and compressive force, can then be the base for a thermal assessment of the abuse of the cell. The findings presented in this manuscript may be used to calculate the resistance in the short circuit area. This could be a new starting point for a thermal assessment in an electric-thermal or electrochemical-thermal model. The occurring temperatures allow conclusions on the risk of certain abuses of the cell.

The results of the internal short experiments with temperature measurement at known electrical parameters (current, resistance, voltage) allow conclusions to be drawn concerning the processes during an internal short event. A correlation between type of short and heat evolution could be established. Furthermore, it is shown that the released short energy influences the amount of separator melt. The surface temperature seemed to be insufficient for internal short detection since some samples showed an internal separator melt without reaching the separator material slumping temperature $\left(>120^{\circ} \mathrm{C}\right)$ at the surface.

This work finally shows that more basic research needs to be carried out in order to achieve a better understanding of internal shorts. Safety concerns are still one of the biggest handicaps for lithium battery usage in the field, especially in the automotive industry.

Acknowledgments: This work has been carried out in the scope of the EinBliC Project, which is funded by the Austrian Research Promotion Agency (FFG), and the leading author was supported by the Clever \& Smart Scholarship granted by the Faculty of Mechanical Engineering of Graz University of Technology. The project is managed by the Vehicle Safety Institute of the Graz University of Technology and the project partners Audi AG, Ingolstadt and AVL List GmbH, Graz. Manufacturing of the samples was performed at the Institute of Chemistry and Technology of Materials of Graz University of Technology.

Author Contributions: Theo Volck performed the preparation of the dummy cells (electrode preparation and cell assembly) supported by Marlena Uitz with her knowledge of the preparation of pouch cells at the laboratory scale. Martin Wilkening and Stefan Freunberger helped to get access to laboratory equipment for the preparation of the dummy cells. Wolfgang Sinz, Hermann Steffan and Gregor Gstrein gave support during the creation of this article with their experience in creating scientific papers and helped to find a proper structure for this article. The resistance measurements were performed by Theo Volck. The operation of the press and the data acquisition and evaluation was supported by Simon F. Heindl and Christoph Breitfuss. Ideas regarding the presented research were provided and a review of the article was performed by Clemens Fink and Alexander Geier as representatives of the project partners.

Conflicts of Interest: The authors declare no conflict of interest. The founding sponsors (FFG and Clever \& Smart) had no role in the design of the study, interpretation of data or in the writing of the manuscript.

\section{Abbreviations}

$\begin{array}{ll}\text { Al } & \text { Aluminium } \\ \text { An } & \text { Anode } \\ \text { Ca } & \text { Cathode } \\ \mathrm{Cu} & \text { Copper } \\ \text { DC } & \text { Direct current } \\ \text { DEC } & \text { Diethyl carbonate } \\ \text { EV } & \text { Electric vehicle } \\ \text { HEV } & \text { Hybrid electric vehicle } \\ \text { LFP } & \text { Lithium iron phosphate } \\ \text { Max. } & \text { Maximum } \\ \text { NCC } & \text { Negative current collector } \\ \text { NMP } & \text { N-methyl-2-pyrrolidon } \\ \text { NREL } & \text { National Renewable Energy Laboratory } \\ \text { OEM } & \text { Original equipment manufacturer } \\ \text { PCC } & \text { Positive current collector }\end{array}$




\section{References}

1. Zhang, Z.J.; Ramadass, P.; Fang, W. Safety of Lithium-Ion Batteries. In Lithium-Ion Batteries-Advances and Applications; Pistoia, G., Ed.; Elsevier: Philadelphia, PA, USA, 2014; Chapter 18; pp. 409-435.

2. Sinz, W.; Feist, F.; Gstrein, G.; Gugler, J.; Tomasch, E.; Breitfuss, C.; Luttenberger, P.; Steffan, H. Concepts for mechanical abuse testing of high-voltage batteries. SAE Tech. Pap. 2012. [CrossRef]

3. Orecchini, F.; Santiangeli, A.; Dell'Era, A. EVs and HEVs Using Lithium-Ion Batteries. In Lithium-Ion Batteries-Advances and Applications; Pistoia, G., Ed.; Elsevier: Philadelphia, PA, USA, 2014; Chapter 10; pp. 205-248.

4. Xia, Y.; Wierzbicki, T.; Sahraei, E.; Zhang, X. Damage of cells and battery packs due to ground impact. J. Power Sources 2014, 267, 78-97. [CrossRef]

5. EinBliC. Entwicklung eines Multiphysikberechnungsmodells von Li-Ion Zellen als Basis zur Steigerung der Batteriecrashsicherheit. Available online: http:/ /www2.ffg.at/verkehr/projektpdf.php?id=1115\&lang=en (accessed on 3 January 2016). (In German)

6. Zhang, C.; Santhanagopalan, S.; Sprague, M.A.; Pesaram, A.A. Coupled mechanical-electrical-thermal modeling for short-circuit prediction in a lithium-ion cell under mechanical abuse. J. Power Sources 2015, 290, 102-113. [CrossRef]

7. Heindl, S.F.; Breitfuss, C.; Ellersdorfer, C.; Feist, F.; Sinz, W. Method for Predicting Li-Ion Cell Reactions due to Mechanical Crash Loads. In Proceedings of the AVL Advanced Simulation Technologies International User Conference, Graz, Austria, 23-25 June 2015.

8. Breitfuss, C.; Sinz, W.; Florian, F.; Gstrein, G.; Lichtenegger, B.; Knauder, C.; Ellersdorfer, C.; Moser, J.; Steffan, H.; Stadler, M.; et al. A “Microscopic" Structural Mechanics FE Model of a Lithium-Ion Pouch Cell for Quasi-Static Load Cases. SAE Int. J. Passeng. Cars Mech. Syst. 2013, 6, 1044-1054. [CrossRef]

9. Sahraei, E.; Hill, R.; Wierzbicki, T. Calibration and finite element simulation of pouch lithium-ion batteries for mechanical integrity. J. Power Sources 2012, 201, 307-321. [CrossRef]

10. Greve, L.; Fehrenbach, C. Mechanical testing and macro-mechanical finite element simulation of the deformation, fracture and short circuit initiation of cylindrical Lithium ion battery cells. J. Power Sources 2012, 214, 377-385. [CrossRef]

11. Gomez, J.; Nelson, R.; Kalu, E.E.; Weatherspoon, M.H.; Zheng, J.P. Equivalent circuit model parameters of a high-power Li-Ion battery: Thermal and state of charge effects. J. Power Sources 2011, 196, 4826-4831. [CrossRef]

12. Fuller, M.E. A battery model for constant-power discharge including rate effects. Energy Convers. Manag. 2014, 88, 199-205. [CrossRef]

13. Miranda, D.; Costa, C.M.; Lanceros-Mendez, S. Lithium ion rechargeable batteries: State of the art and future needs of theoretical models and simulations. J. Electroanal. Chem. 2014, 739, 97-110. [CrossRef]

14. Maleki, H.; Howard, J.N. Internal short circuit in Li-ion cells. J. Power Sources 2009, 191, 568-574. [CrossRef]

15. Kim, G.-H.; Smith, K.; Pesaran, A. Lithium-Ion Battery Safety Study Using Multi-Physics Internal Short-Circuit Model. In Proceedings of the 5th Intl. Symposium on Large Lithium-Ion Battery Technology and Application in Conjunction with AABC09, Long Beach, CA, USA, 9-10 June 2009.

16. Kalupson, J.; Luo, G.; Shaffer, C.E. AutoLion ${ }^{\mathrm{TM}}$ : A thermally coupled simulation tool for automotive Li-ion batteries. SAE Tech. Pap. 2013. [CrossRef]

17. Fang, W.; Ramadass, P.; Zhang, Z. Study of internal short in a Li-ion cell-II. Numerical investigation using a 3D electrochemical-thermal model. J. Power Sources 2014, 248, 1090-1098. [CrossRef]

18. Chiu, K.C.; Lin, C.H.; Yeh, S.F.; Lin, Y.H.; Chen, K.C. An electrochemical modelling of lithium-ion battery nail penetration. J. Power Sources 2014, 251, 254-263. [CrossRef]

19. Keyser, M.; Long, D.; Jung, Y.S.; Pesaran, A.; Darcy, E.; Mccarthy, B.; Patrick, L.; Kruger, C. Development of a Novel Test Method for On-Demand Internal Short Circuit in a Li-Ion Cell. In Proceedings of the Large Lithium-Ion Battery Technology Application Symposium, Advanced Automotive Battery Conference, Pasadena, CA, USA, 25-28 January 2006.

20. Holm, R. Electric Contacts: Theory and Application; Springer: Berlin, Germany, 1967. 
21. Santhanagopalan, S.; Ramadass, P.; Zhang, Z. Analysis of internal short-circuit in a lithium ion cell. J. Power Sources 2009, 194, 550-557. [CrossRef]

22. Orendorff, C.J.; Ganesan, N.; Roth, P.E. Experimental triggers for internal short circuits in lithium-ion cells. J. Power Sources 2011, 196, 6554-6558. [CrossRef]

(C) 2016 by the authors; licensee MDPI, Basel, Switzerland. This article is an open access article distributed under the terms and conditions of the Creative Commons by Attribution (CC-BY) license (http:/ / creativecommons.org/licenses/by/4.0/). 